\title{
PERANAN KOMPONEN TIANG DIAGONAL DI RUMAH ADAT TRADISIONAL KAJANG DALAM MENGHADAPI BEBAN LATERAL
}

\author{
Suci Qadriana Ramadhani*, Sudarman Abdullah \\ Jurusan Teknik Arsitektur \\ Fakultas Sains dan Teknologi UIN Alauddin Makassar \\ J1. Sultan Alauddin No. 63, Kabupaten Gowa, Sulawesi Selatan. 92113 \\ *E-mail: suciq.ramadhani@ gmail.com
}

\begin{abstract}
Abstrak: Pengetahuan struktural yang diterapkan pada rumah tradisional di Indonesia hampir semuanya melalui tahap coba-coba melalui peninggalan arsitektural masyarakat sebelumnya yang mirip dengan struktur dan konstruksi rumah tradisional Kajang. Warisan budaya menciptakan identitas lokal yang melekat pada komunitas. Bentuk dan konstruksi kolom rumah di Desa Tanah Toa, Kecamatan Kajang, Kabupaten Bulukumba memiliki ciri khas tersendiri. Hal yang menarik dari rumah adat Kajang adalah terdapat tiang-tiang yang sengaja dipasang secara diagonal atau menggunakan tiang yang dibengkokkan dan dibuat berpasangan berlawanan arah. Penelitian ini mencoba melihat secara ilmiah peran tiang diagonal sebagai komponen struktur untuk menahan beban yang timbul pada bangunan khususnya beban lateral.
\end{abstract}

Kata Kunci: beban lateral, kolom, rumah adat Kajang

\section{PENDAHULUAN}

$\mathrm{B}$ encana merupakan hal yang datangnya tidak dapat diduga mengenai dimana dan kapan terjadinya. Terjadinya suatu bencana tentunya memiliki maksud tertentu. Dapat pula menjadi suatu peringatan kepada manusia untuk menjaga alam agar tidak rusak. Salah satu negara yang memiliki resiko bencana tinggi adalah Indonesia. Berdasarkan data yang dikeluarkan oleh Badan Perserikatan Bangsa-Bangsa untuk Strategi Internasional Pengurangan Risiko Bencana (UN-ISDR) menyatakan bahwa Indonesia menjadi negara yang paling rawan terhadap bencana di dunia. Tingginya posisi Indonesia ini dihitung dari jumlah manusia yang terancam risiko kehilangan nyawa bila bencana alam terjadi.

Manusia tidak akan dapat menghentikan terjadinya suatu bencana alam. Manusia juga tetap akan mengalami kerugian besar ketika bencana terjadi, namun manusia dapat menghindari dampak yang lebih besar seperti berusaha memperkecil kemungkinan adanya korban jiwa. Bencana alam merupakan rangkaian peristiwa alam yang mengancam kehidupan manusia. Terkadang bencana alam juga dapat terjadi dari konsekuensi keterlibatan manusia pada perusakan alam yang ada.

Salah satu solusi untuk mengurangi dampak bencana alam yang besar adalah dengan membangun hunian yang ramah dengan alam sekitarnya. Hunian yang telah teruji interaksinya dengan alam sekitar melalui proses waktu yang lama adalah rumah tradisional. Rumah tradisional telah melalui proses tradisi atau serah terima wujud kebudayaan dari pendahulu kepada keturunannya selama turun temurun. Rumah tersebut 
telah mengalami trial and error dengan lingkungan alam sekitar sehingga menghasilkan model purwarupa (prototipe) yang dikembangkan secara massal di wilayah yang masih memegang erat adat tradisi tersebut.

Rumah adat tradisional merupakan warisan budaya arsitektural yang patut dijaga kelestariannya, di samping karena merupakan identitas budaya lokal indonesia juga karena terdapat proses pembelajaran yang panjang dalam menghasilkan bentuk dan konstruksi rumah yang tahan terhadap iklim lokal, mampu bersinergi dengan lingkungan dan tetap memberikan rasa aman dan nyaman kepada penghuninya dalam waktu yang lama. Warisan budaya arsitektural ini menjadi tantangan bagi kalangan akademisi untuk menggali nilai-nilai kearifan lokal yang terdapat pada rumah tradisional tersebut dan mencari tahu fungsi nilai kearifan lokal tersebut dan hubungannya dengan alam sekitar sehingga lebih tanggap terhadap bencana alam yang mungkin dapat terjadi.

Salah satu wilayah yang masih menjaga keaslian wujud rumahnya sesuai dengan rumah yang dibangun oleh leluhurnya terdapat di Desa TanahToa, Kelurahan Kajang, Kecamatan Bulukumba. Bentuk dan konstruksi rumah yang berada dalam Kawasan Adat Kajang tersebut masih mengikuti aturan adat dan tradisi budaya membangun yang diwariskan dari pendahulunya hingga sekarang. Salah satu komponen yang dibangun berdasarkan pengetahuan lokal masyarakat setempat dan ketersediaan bahan bangunan adalah tiang rumah atau di Kajang dikenal dengan istilah benteng.

Tiang dalam dunia arsitektur merupakan komponen yang penting dalam menjaga kekuatan struktural sehingga rumah dapat berdiri dengan stabil dan tahan terhadap goncangan yang ada. Penelitian ini ingin menyajikan objek utama struktur rumah masyarakat Kajang yaitu tiang (benteng) rumah adat tersebut dan menjelaskan kekuatan lateral tiang tersebut dari pandangan kajian literatur sebagai sumber data pendukung.

\section{METODE PENELITIAN}

\section{Rancangan Penelitian}

Penelitian ini menggunakan paradigma rasionalistik dengan menggunakan argumentasi atas empiri melalui metode kualitatif. Sehingga dilaksanakan survei lapangan dan olah pustaka. Sasaran dari penelitian ini untuk mengetahui prosedur yang digunakan dalam merancang rumah Kajang khususnya mengenai tiang (benteng) atau komponen kaki-kaki yang digunakan dalam rumah adat.

\section{Pelaksanaan Penelitian}

Secara administratif, lokasi penelitian berada di Dusun Benteng, Desa Tana Toa, Kecamatan Kajang, Kabupaten Bulukumba, Provinsi Sulawesi Selatan. Jarak dari Kota Makassar ke lokasi penelitian sekitar $250 \mathrm{~km}$ ke arah tenggara. Dusun Benteng dipilih sebagai lokasi penelitian dengan alasan bahwa di tempat tersebut, tradisinya masih melekat dan rumah-rumah yang ada dalam lokasi tersebut masih terjaga keasliannya.

\section{Teknik pengumpulan data}

Sugiyono (2017) menerangkan bahwa populasi merupakan lokasi penelitian yang meliputi subjek dan objek penelitan yang dianggap pantas atau memenuhi standar dalam segi kualitas dan kondisi tertentu untuk diperhatikan dan dikaji untuk kemudian dihasilkan simpulan. Penelitian ini mengambil sampel rumah-rumah di Kawasan Adat Kajang yang biasa disebut dengan istilah Kajang-Dalam yang membedakan diri dengan Kajang-Luar dengan ciri gaya hidup dan bangunan yang masih terjaga keaslian wujudnya 
seperti wujud budaya arsitektur pendahulunya sejak turun temurun dan tidak memasukkan teknologi dan budaya dari luar.

Teknik pengumpulan data yang digunakan meliputi dua hal, yaitu kualitas instrumen penelitian dan kualitas pengumpulan data. Instrumen penelitian yang didapat dari hasil wawancara tidak terstruktur dan tinjauan terhadap rumah Kajang akan divalidasi dengan triangulasi data oleh arsitek, masyarakat dan penelitian terkait lainnya. Dalam Sugiyono (2007) tentang kualitas data penelitian, dijelaskan bahwa dalam penelitian terdapat data berupa: hasil wawancara dengan arsitek Kajang, hasil wawancara dengan ketua adat dan tokoh penting masyarakat Kajang serta kajian literatur tentang struktur lateral bangunan

\section{HASIL DAN PEMBAHASAN}

\section{Arsitektur Tradisional}

Arsitektur vernakular memiliki sebuah kekonsistenan dari segi fisik bangunan seperti pada pemilihan material, konstruksi, ornamen, bentuk, dan dimensi. Kekonsistenan tersebut merupakan hasil dari penerimaan masyarakat di wilayah tersebut, sehingga kekonsistenan tersebut menjadi pembiasaan yang berkembang menjadi sebuah tradisi. Salah satu arsitektur vernakuler yang dikenal adalah arsitektur Kajang. Fisik rumah Kajang merupakan hasil adaptasi dalam menunjukkan keselarasan terhadap alam sekitarnya. Rumah Kajang merupakan rumah adat berkonstruksi panggung yang ditujukan untuk menghadapi kondisi alam tropis di nusantara. Arsitektur tradisional merupakan arsitektur yang terbentuk dari adanya proses kekonsistenan aturan secara turun temurun dan tradisi di dalamnya sedangkan arsitektur vernakuler merupakan arsitektur yang timbul dari kebudayaan dan kondisi alam suatu wilayah, di luar proses tradisi tersebut.

Rumah merupakan wadah yang berfungsi untuk melindungi penghuninya dari serangan yang datang dari luar. Fungsi perlindungan ini mengisyaratkan agar rumah memiliki konstruksi yang bisa bertahan dalam menghadapi serangan tersebut. Konstruksi bangunan yang kuat berkontribusi besar terhadap kekuatan bangunan. Selain konstruksi, material bangunan juga memiliki andil dalam menentukan kekuatan bangunan terhadap serangan dari luar.

Hampir seluruh material rumah adat tradisional yang ada di Indonesia terbuat dari material kayu yang diperoleh dari alam sekitar. Kebanyakan rumah adat tersebut juga tahan terhadap cuaca dan bencana. Seperti rumah adat yang berada di Aceh yang terkena bencana gempa dan tsunami. Namun setelah ditelusuri, rumah yang bertahan pasca bencana tersebut adalah rumah adat yang berkonstruksi panggung dan berbahan kayu.

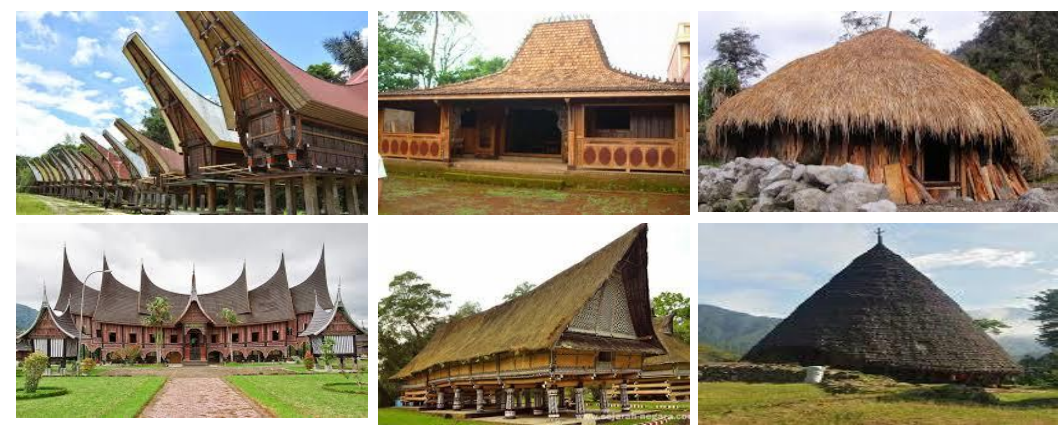

Gambar 1. Rumah- rumah adat Indonesia berbahan kayu 
Pandangan masyarakat Kajang bahwa hunian dan manusia merupakan bagian dari alam, sehingga dalam merancang hunian, masyarakat Kajang senantiasa menyelaraskan dengan alam. Rumah adalah suatu tempat dimana terdapat keselarasan antara dunia atas (ratena linoa) yaitu pencipta, dunia tengah (tangngana linoa) yaitu manusia dan dunia bawah (rawana linoa) tempat kotor.

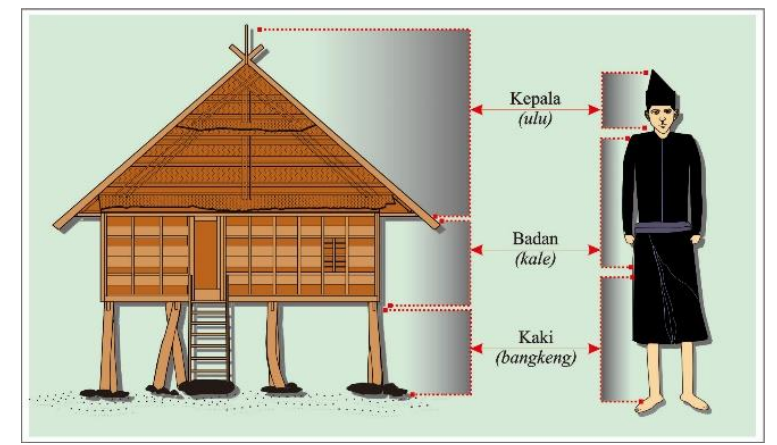

Gambar 2. Pembagian rumah Kajang secara vertikal (Ramadhani, 2015)

Berdasarkan kepercayaan kehidupan orang Kajang, terdapat hubungan antara nilai filosofi dan arsitektur rumah Kajang yang menjadikan rumah adatnya kuat terhadap ancaman bencana alam seperti angin ribut, dan gempa. Kunci utama kekuatan tahan bencana alam pada rumah Kajang terdapat pada tiang-tiang yang menopang beban rumah. Hasil kajian dalam penelitian ini diharapkan dapat menjadi salah satu sumber pengembangan ilmu arsitektur khususnya arsitektur vernakular dalam menampilkan kearifan lokalnya sekaligus sebagai proses ketahanan bangunan terhadap bencana.

\section{Kestabilan Komponen Struktur}

Kekuatan dan kekakuan komponen struktur memiliki kaitan dengan gaya tumpuan, torsi, geser, lentur, tekan, tarik dan deformasi yang disebabkan oleh adanya beban yang diterima. Kestabilan struktur dibutuhkan agar bisa menghadapi segala kondisi pembebanan. Pada dasarnya setiap elemen struktur dapat mengalami deformasi (perubahan bentuk) apabila mendapatkan beban. Jika strukturnya stabil, maka deformasi yang akan timbul dari penerimaan beban, cenderung kecil namun bila strukturnya kurang stabil maka deformasi cenderung besar dan akan bertambah sejalan dengan bertambahnya beban. Hal tersebut timbul karena sistem tidak dapat membuat gaya-gaya internal untuk mengembalikan bentuk ke bentuk semula, ketika bebannya sudah dihilangkan. Pada struktur yang tidak stabil akan mudah mengalami keruntuhan ketika dibebani. Cara untuk membuat struktur menjadi sistem yang stabil di antaranya adalah dengan cara penambahan elemen diagonal pada struktur sehingga tidak akan mengalami deformasi menjadi jajaran genjang, cara yang lainnya adalah dengan menambahkan bidang geser dan titik hubung kaku. Pada rakitan komponen struktur, salah satu atau lebih komponen yang menjamin kestabilan harus digunakan agar struktur tidak runtuh secara lateral. Satu elemen struktur dapat didesain dengan menggunakan satu cara yang menjamin stabilitas struktur untuk satu arah lateral, dan cara lain untuk arah lainnya. (Ariestadi, 2008).

Satuan struktural utama dapat terdiri atas kombinasi elemen-elemen linier/garis, bidang/permukaan, vertikal maupun horisontal, baik tunggal maupun rangkaian rangka. Satuan struktural yang biasa dijumpai dapat dibedakan menjadi: (1) Sistem yang membentang secara horizontal; (2) Sistem yang membentang secara vertikal; dan (3) Sistem tumpuan lateral. 
Beban-beban yang bekerja pada arah horisontal seperti angin atau gempa dapat menyebabkan struktur runtuh secara lateral. Struktur dinding dapat memikul beban-beban tersebut, sebaliknya sistem balok dan kolom membutuhkan elemen-elemen pemikiul lain misalnya elemen linier diagonal.

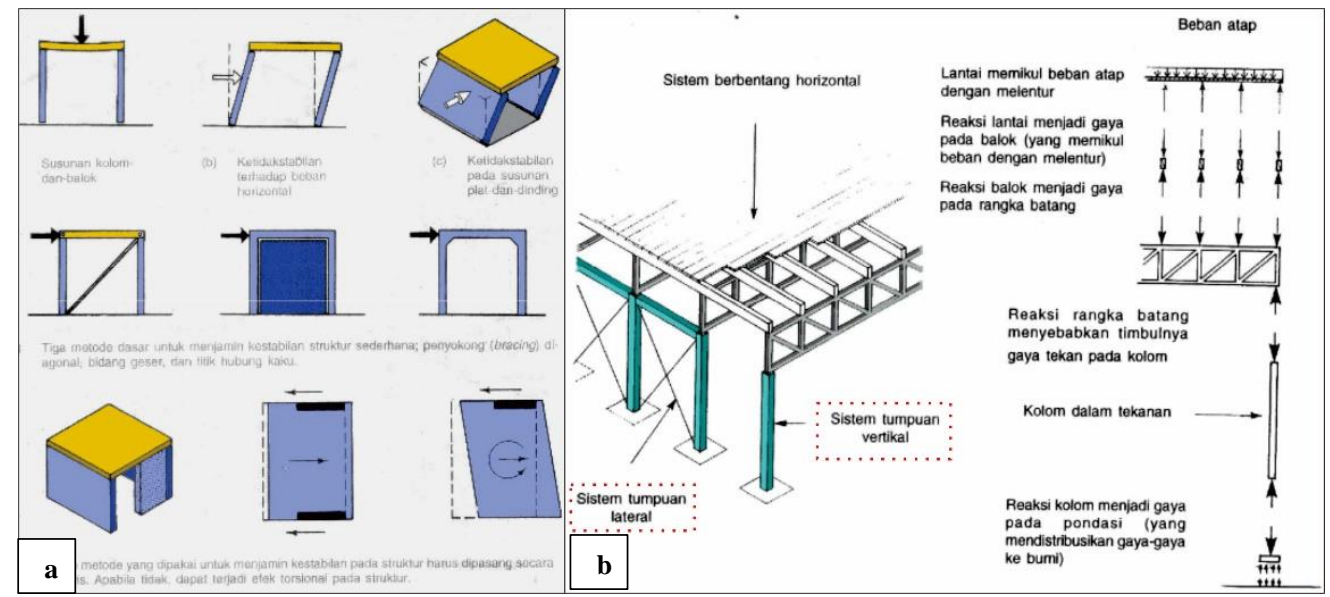

Gambar 3. a) Analisa kestabilan struktur; b) Susunan sistem struktur penahan bentang horisontal untuk bentang lebar atau panjang (Schodek, 1999)

\section{Struktur Bangunan Rumah Kajang}

Struktur bangunan merupakan bagian dari bangunan yang menentukan kekuatan dan kekakuan suatu bangunan. Fungsinya adalah untuk menyalurkan beban-beban yang berada di dalam bangunan, maupun beban bangunan itu sendiri, beban mati dan beban hidup agar bangunan tersebut tidak mengalami keruntuhan dan bisa bertahan. Struktur untuk menyalurkan beban-beban tersebut ditumpu oleh beberapa elemen-elemen yang berfungsi dalam suatu sistem struktur. Penentuan dimensi, bentuk serta penyusunan komponen-komponen tersebut dilakukan berdasarkan aturan turun-temurun dari leluhur yang diturunkan melalui pengajaran non-formal bagi masyarakat Kajang.

\section{Istilah dalam Konstruksi Rumah Kajang}

Hasil wawancara dengan ammatoa (ketua adat) dan uragi (pembuat rumah), diperoleh istilah yang digunakan dalam penamaan setiap komponen struktural rumah tradisional Kajang sebagaimana ditunjukkan pada Tabel 1.

Tabel 1. Deskripsi dan material untuk komponen rumah tradisional Kajang

\begin{tabular}{|c|c|c|}
\hline Komponen Struktural & Material & Deskripsi \\
\hline Atak, timba lajara & $\begin{array}{l}\text { Raung kaluku lohe } \\
\text { (Daun rumbia) sebanyak } \\
400 \text { pauruk (lembar) }\end{array}$ & Elemen penutup atap dan susunan atap depan \\
\hline Buhungang & Kayu bitti & Balok kayu untuk bubungan atap \\
\hline Anjong & $\begin{array}{l}\text { Pahatan papan, } \\
\text { umumnya berbentuk L }\end{array}$ & $\begin{array}{l}\text { Ornamen atap, terletak di kedua ujung } \\
\text { bubungan atap }\end{array}$ \\
\hline Rinring & $\begin{array}{l}\text { Papan kayu atau bisa } \\
\text { juga tekre (bambu) }\end{array}$ & $\begin{array}{l}\text { Dinding rumah yang materialnya disusun } \\
\text { secara horizontal sebagai elemen pembatas } \\
\text { dan pelindung badan rumah }\end{array}$ \\
\hline $\begin{array}{l}\text { Benteng: } \\
\text { - Benteng ri ulu } \\
\text { - Benteng ri tangnga } \\
\text { - Benteng pakkai } \\
\text { - Benteng sonrong }\end{array}$ & $\begin{array}{l}\text { Balok kayu bentuk } \\
\text { persegi yang terbuat dari } \\
\text { kayu bitti }\end{array}$ & $\begin{array}{l}\text { Balok lurus vertikal, dan balok bengkok } \\
\text { yang tampak diagonal mendukung struktur } \\
\text { utama rumah }\end{array}$ \\
\hline
\end{tabular}




\begin{tabular}{|c|c|c|}
\hline $\begin{array}{l}\text { - Benteng tala-tala } \\
\text { - Benteng ana }\end{array}$ & & \\
\hline Dasere & Kayu bitti atau bambu & $\begin{array}{l}\text { Lantai bambu (dasere) atau lantai kayu } \\
\text { (dapara) yang terbuat dari papan kayu yang } \\
\text { dijejer dan berjarak/celah }\end{array}$ \\
\hline Padongkok & Balok kayu bitti & $\begin{array}{l}\text { Balok utama yang dijepit oleh tiang/ } \\
\text { menghubungkan struktur tiang dan dipasang } \\
\text { melintang di bagian atas badan rumah }\end{array}$ \\
\hline Amulu & Balok kayu bitti & $\begin{array}{l}\text { Balok anak yang diletakkan berjejer di atas } \\
\text { balok padongkok }\end{array}$ \\
\hline Pappatuntulang & Balok kayu bitti & $\begin{array}{l}\text { Balok utama yang dijepit oleh tiang/ } \\
\text { menghubungkan struktur tiang di padang } \\
\text { membujur di bagian bawah badan rumah. }\end{array}$ \\
\hline Hulusu & $\begin{array}{l}\text { Balok kayu bitti dimensi } \\
\text { kecil }\end{array}$ & $\begin{array}{l}\text { Rangka lantai yang diletakkan berjejer di } \\
\text { atas balok pappatuntulang }\end{array}$ \\
\hline Timbaho & Papan kayu bitti & $\begin{array}{l}\text { Plafon yang terdiri dari susunan papan kayu } \\
\text { yang dijejer dan dirapatkan }\end{array}$ \\
\hline Pappamuntulang & Balok kayu bitti & $\begin{array}{l}\text { Papan arah melintang yang dipasang untuk } \\
\text { menandai latta ri tangnga (petak tengah) dan } \\
\text { latta ri olo (petak belakang) }\end{array}$ \\
\hline Panampu & Papan kayu bitti & $\begin{array}{l}\text { Penanda batas antara latta ritangnga dan } \\
\text { latta riboko }\end{array}$ \\
\hline Tontongang & $\begin{array}{l}\text { Papan kayu bitti atau } \\
\text { bambu }\end{array}$ & $\begin{array}{l}\text { Jendela/bukaan pada dinding. Untuk } \\
\text { material kayu (dimensi bukaan cenderung } \\
\text { lebih besar) atau bambu (dimensi bukaan } \\
\text { cenderung lebih kecil) }\end{array}$ \\
\hline Anna & Kayu bitti & $\begin{array}{l}\text { Tiap rumah memiliki satu pintu geser papan } \\
\text { kayu di bagian depan, yang letaknya } \\
\text { menjorok ke kanan. }\end{array}$ \\
\hline Tukak & Papan kayu bitti’ & $\begin{array}{l}\text { Tangga yang terdiri atas susunan anak tangga } \\
\text { dari papan kayu tebal dengan jumlah } \\
\text { bilangan ganjil }\end{array}$ \\
\hline
\end{tabular}

Sumber: Hasil pengamatan di lapangan dan wawancara

Rumah di dalam Kawasan Adat Kajang umumnya menggunakan kayu bitti dalam membuat rumahnya. Kayu bitti ini juga digunakan sebagai bahan untuk membuat kapal pinisi di desa lainnya di Bulukumba. Kayu ini berasal dari pohon khas sulawesi yaitu bitti (Vitex cofassus). Di beberapa tempat di bulukumba, pohon bitti ditanam sebagai hutan rakyat. Pohon ini juga dikenal dengan nama sassuwar, gofasa, bitum, gupasa dan bana.

\section{Konstruksi tiang (benteng) rumah Kajang}

Masyarakat Kajang memiliki pertimbangan struktural yang berasal dari pemikiran pendahulu yang diwariskan dalam wujud tradisi budaya. Warisan adat budaya tersebut dipegang teguh dan diwariskan kepada keturunannya dalam bentuk pasang (aturan tak tertulis yang mengikat masyarakat Kajang) yang mengatur tata hidup masyarakat Kajang mulai dari perilaku, pakaian, cara mengolah makanan dan kebutuhan lainnya, filosofi dan orientasi rumah (ke arah barat), hingga cara mendirikan bangunan dan cara berinteraksi dengan baik dengan alam sekitar. Pokok bahasan dalam penelitian ini berkonsentrasi pada konstruksi rumah Kajang terkhusus pada bagian tiang/kolom yang dikenal dengan istilah benteng. Terdapat 16 tiang penopang rumah Kajang dimana tiang tersebut tersusun menjadi 4 baris (saluru') dan lajur, sehingga membentuk 3 petak (latta') pada badan rumah baik secara melintang maupun membujur. Jika kita memandang rumah dari depan, tiang tersebut dimulai dari bagian depan sebelah kanan yang dinamakan benteng riulu, 
kemudian benteng tangnga, kemudian benteng pakkai' lalu benteng sonrong. Keempat komponen tiang tersebut dengan tingkat kerumitan dan dibuat atas dasar aturan membuat rumah yang telah diwarisi oleh para uragi (pembuat rumah). Tiang-tiang tersebut memiliki urutan saat akan dibangun:

a) Tiang pertama yang dibangun merupakan tiang di lajur pinggir sebelah kiri yaitu benteng ri ulu. Benteng ri ulu yang dimaksud adalah benteng yang kedudukannya paling tinggi. Dikatakan sebagai pemimpin tiang-tiang yang lain. Terkadang tiang yang paling pinggir/berada di sudut tersebut juga dinamakan benteng kacucu karena posisinya. Terkadang juga disebut pokok balla yang memiliki filosofi laki-laki (penjaga tiang) atau komandan keluarga. Tiang ini yang pertama kali dibangun dan dipilih batang kayu yang lurus.

b) Tiang yang kedua dibangun adalah benteng ri tangnga yaitu tiang yang sering juga disebut sebagai possi bola yang memiliki filosofi sebagai perempuan atau ibu (anrong) dari tiang-tiang yang lain di depannya (benteng ana'). Oleh sebab itu, tiang ini cenderung lebih besar dimensinya dibandingkan dengan tiang-tiang yang lain dan cenderung bengkok.

c) Tiang ketiga yang dibangun adalah benteng pakkai (tiang pengait) yang berada persis di sebelah benteng ri tangnga. Tiang ini cenderung dipilih yang bengkok ke arah yang berlawanan dari arah bengkoknya benteng ri tangnga.

d) Tiang keempat yang dibangun adalah benteng sonrong yang berada persis di sebelah tiang pengait. Tiang ini umumnya dipilih dari balok kayu yang lurus seperti Benteng ri ulu. Setelah tiang-tiang ini didirikan, lalu sisa tiang yang lainnya didirikan sesuai posisi, bentuk, arah kemiringan dan kondisi tanahnya.

3. Spasial Komponen-Komponen Tiang Dalam Rumah Kajang

Rumah di kawasan adat masyarakat Kajang memiliki 16 tiang yang diatur dengan koordinat 4 x 4 sehingga dari depan ke belakang, rumah terbagi atas 3 petak. Dari samping kiri ke samping kanan juga terbagi atas 3 petak. Tata letak tiang-tiang rumah Kajang beserta penamaannya ditunjukkan pada Gambar 4 .

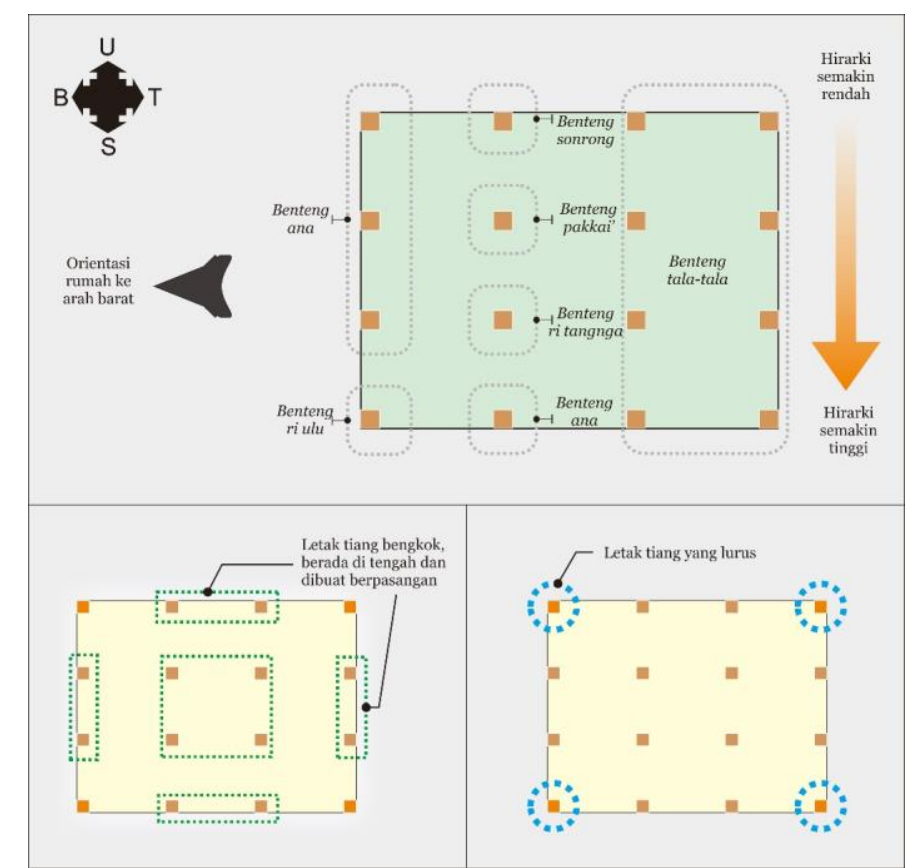

Gambar 4. Tata letak tiang-tiang rumah Kajang beserta penamaannya 
Pada umumnya tiap sambungan konstruksi kayu pada rumah adat, disatukan menggunakan pasak kayu. Tinggi tiang relatif berkisar 5-6 m untuk ukuran metrik, tetapi tinggi ini relatif karena diukur berdasarkan antropometri/standar ukuran tubuh pemilik rumah. Tiang ditanam sekitar $1 \mathrm{~m}$ ke dalam tanah dengan alasan filosofis penyatuan rumah dengan bumi sebagai ibu (anrong) dari rumah. Secara antropometri menurut skala ukuran tubuh manusia yaitu tinggi dari kepala hingga kaki + lengan (tinggina bangkeng na ulu + si lappa) untuk ukuran tinggi kolong rumah (siring) dan ukuran badan rumah. Tiang-tiang di rumah Kajang umumnya terbuat dari balok kayu lurus untuk diletakkan pada posisi di sudut-sudut rumah. Sedangkan pada posisi tengah, tiang cenderung terbuat dari balok kayu bentuk yang unik (balok bengkok). Terkadang pula untuk posisi tengah tersebut, bila balok kayunya lurus, maka dibuat miring dan berpasangan dengan tujuan agar bisa memperkokoh bangunan dan mengurangi goncangan yang dapat terjadi. Pemilihan bentuknya didasari atas kebutuhan rumah, ukuran pemilik dan pertimbangan uragi (pembuat rumah).

Tinggi tiang di bagian tengah dan tinggi tiang di ujung atau sudut tidak sama. Hal ini disebabkan karena tiang di bagian tengah dipasang sedikit miring/memiliki sudut beberapa derajat, sehingga tiang tengah memiliki ukuran yang lebih panjang. Pada zaman dulu, pembuat rumah (uragi) sengaja mencari batang kayu yang bengkok dengan tujuan bahwa batang kayu yang bengkok tersebut, apabila didirikan berpasangan maka konstruksi rumah akan menjadi lebih kuat dan tahan terhadap goncangan. Pernyataan ini diperoleh dari pernyataan ketua adat Kajang, yang berbunyi: "Anjo bentenga bengko'a siti'galli, situ'rangi, nihoja'i bengko'a ka kua'i”, yang artinya "Tiang (bengkok) seperti itu saling menopang karena berpasangan, dicari yang bengkok agar kuat" (Hasil wawancara dengan Ammatoa di Dusun Benteng, 2019).

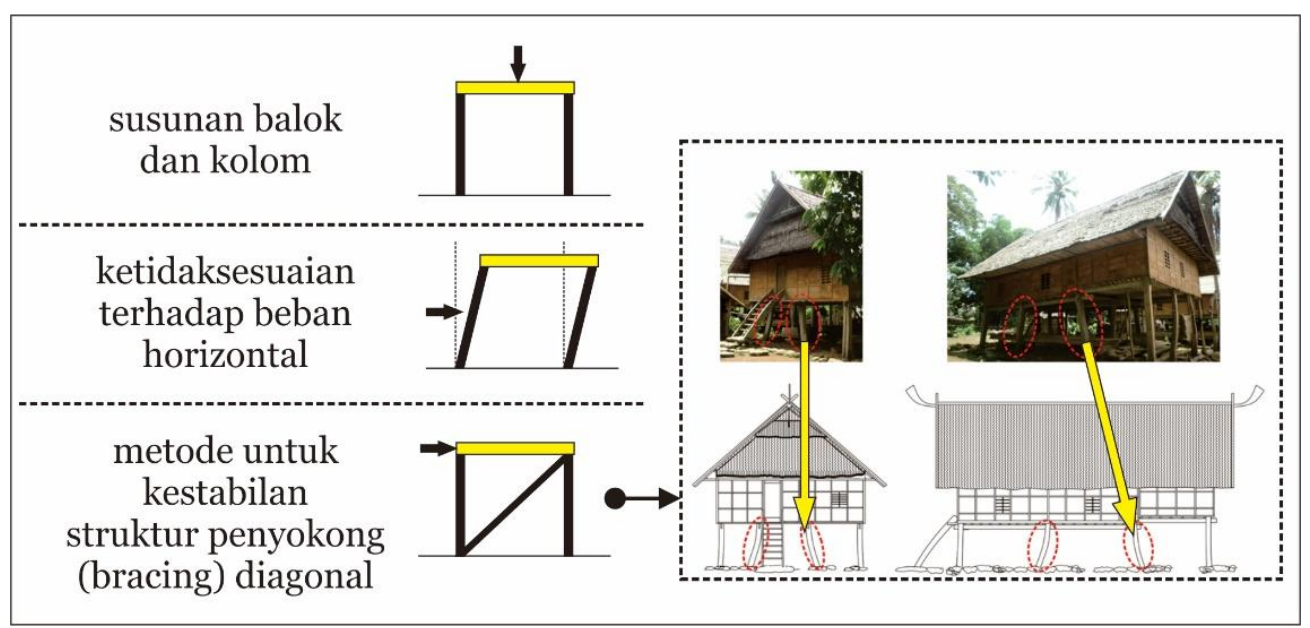

Gambar 5. Analisis kestabilan struktur tiang bengkok yang berpasangan (Ramadhani, 2019)

Pemilihan tiang yang bengkok dan berpasangan dalam pandangan ilmu arsitektur sendiri, dapat dimengerti sebagai usaha meningkatkan kestabilan struktur. Bagian struktur yang tidak tersusun dengan baik dapat menyebabkan keruntuhan secara internal. Kestabilan struktur diperlukan untuk menjamin stabilitas bangunan di segala kondisi pembebanan yang mungkin terjadi. Semua struktur akan mengalami perubahan bentuk atau deformasi apabila menerima pembebanan. Mekanisme pemikul beban, aksi rangka (hubungan kaku) atau dengan penambahan elemen diagonal dapat digunakan untuk membuat struktur menjadi stabil. Penambahan elemen diagonal adalah salah satu langkah untuk membuat struktur menjadi lebih stabil. Dalam hal ini yang diterapkan oleh 
komponen tiang pada rumah Kajang untuk memperstabil kekuatan struktur maka diterapkan elemen diagonal tersebut untuk menghadapi beban lateral. Hal tersebut diwujudkan dengan tiang yang terbuat dari balok kayu bengkok yang diaplikasikan di rumah Kajang. Tiang yang bengkok dan berpasangan tersebut menyerupai elemen diagonal yang berfungsi untuk memperkuat struktur yang dimaksud dalam kajian teori penelitian ini.

\section{KESIMPULAN}

Konstruksi tiang rumah Kajang memiliki variasi bentuk balok, yaitu balok kayu yang lurus dan balok kayu bengkok. Bentuk ini tergantung pada posisinya pada rumah. Kemiringan, tinggi serta pasangannya ditentukan oleh uragi (pembuat rumah). Pemilihan bentuk kayu yang bengkok pada rumah Kajang sengaja dipilih dan digunakan untuk memperkuat konstruksi agar dapat menahan goncangan yang kurang optimal bila hanya ditahan dengan komponen struktur yang vertikal. Tiang yang bengkok atau yang dipasang miring dimaksudkan untuk menghadapi beban lateral yang dapat terjadi pada rumah Kajang.

\section{DAFTAR PUSTAKA}

Alexander, C. (1977). A pattern language. NewYork: Oxford University Press.

Ariestadi, D. (2008). Teknik struktur bangunan (Jilid 2). Jakarta: Direktorat Pembinaan Sekolah Menengah Kejuruan.

Prasetyo, F. (2013). Manufacturing geniusloci of indigenous Nias architecture. Bandung: Universitas Padjajaran.

Ramadhani, S. (2015). Tanda dan Simbol Arsitektural Rumah Tradisional Kajang Dusun Benteng, Desa Tanah Toa, Kecamatan Kajang, Kabupaten Bulukumba, Sulawesi Selatan. [Tesis]. Yogyakarta: Universitas Gadjah Mada.

Sugiono. (2007). Metode penelitian pendidikan: Pendekatan kuantitatif, kualitati, dan R\&D. Bandung: Alfabeta.

Zebua, N. C (2016). Kajian etnomatematika dalam fondasi arsitektur rumah adat Omo Sebua-Nias Utara. https://fdokumen.com/.

Bakhtiar., Judi, O., Waani., \& J. Rengkung. (2014). Tipe teori pada arsitektur nusantara menurut Josef Prijotomo. Media Matrasain, 11 (2), 32-47.

Takwim, S. (2013). Kearifan Lokal Suku Kajang dalam Penataan Ruang. [Tesis]. Yogyakarta: Program Pascasarjana Fakultas Teknik Universitas Gadjah Mada.

Tika, Z. (2013). Ammatoa. Makassar: Lembaga Kajian Budaya Sulawesi Selatan.

Tjahjono, G. (2002). Indonesia Heritage. Jakarta: Grolier Internasional. 